\title{
Simultaneous Bilateral Hip Fractures in an Elderly Patient in the Absence of Bone Disease: A Case Report
}

\author{
Ahmed Ayman Habis ${ }^{1,2}$, Gavin CA Wood ${ }^{1}$ \\ ${ }^{1}$ Department of Orthopaedic Surgery, Kingston General Hospital, Queens University, Kingston, Ontario, Canada \\ ${ }^{2}$ Department of Orthopaedic Surgery, King Abdulaziz University, Jeddah, Saudi Arabia
}

*Corresponding Author: Ahmed Ayman Habis, Department of Orthopaedic Surgery, Kingston General Hospital, Queens University, Kingston, Ontario, Canada.

\section{Received date: September 9, 2021; Accepted date: October 4, 2021; published date; January 04, 2022}

Citation: Ahmed Ayman Habis and Gavin CA Wood (2022) Simultaneous bilateral hip fractures in an elderly patient in the absence of bone disease: A case report; J, Surgical Case Reports and Images 5(1); DOI: 10.31579/2690-1897/096

Copyright: (c) 2022, Ahmed Ayman Habis, This is an open access article distributed under the Creative Commons Attribution License, which permits unrestricted use, distribution, and reproduction in any medium, provided the original work is properly cited.

\begin{abstract}
Case: Eighty-three years old female patient who sustained a simultaneous bilateral hip fractures after a mechanical fall. The bilateral nature of the problem was not appreciated by the emergency team and was found after the orthopedic consultation. The patient underwent a single stage bilateral cemented bipolar hemiarthroplasty without perioperative complications.

Conclusion: Simultaneous bilateral hip fractures in elderly are not commonly encountered after a low energy mechanism but early recognition of this diagnosis is important to optimize perioperative management. Having bilateral cemented stems did not lead to any significant cardiopulmonary complications as can often be concerned with so called cement syndrome.
\end{abstract}

Keywords: simultaneous bilateral hip fractures; cemented bipolar; hemiarthroplasty, neck of femur

\begin{abstract}
Abbreviations: ASA, American society of Anesthesia; ECG, electrocardiogram; PRBC, packed red blood cells; AP, anteroposterior;
\end{abstract}

\section{Introduction}

Hip fractures are very common in elderly people, but simultaneous bilateral hip fractures are rarely encountered. Simultaneous bilateral hip fractures could be seen in young people with pathological bone like severe osteoporosis, chronic renal failure or hyperparathyroidism [1]. Simultaneous bilateral hip fractures are more commonly associated with tonic-clonic seizures, electrical shocks and high energy trauma, but some cases were reported only after simple falls [2]. However, simultaneous bilateral hip fractures after simple fall in the absence of bone metabolic disease or cancer is rarer and only few such cases are encountered in the literature [3]. In fact, only five cases up to our knowledge were described for simultaneous bilateral hip fractures following low energy mechanism in the absence of bony disease [3].

In general, simultaneous bilateral hip fractures are not extremely uncommon and clinicians should be aware of their possibility especially in elderly people after simple falls to make sure they do not get missed. Early recognition of simultaneous bilateral hip fractures can be difficult in some cases especially in non-verbal or unconscious people or patients with dementia. Moreover, delayed or missed diagnosis secondary to the rareness of this diagnosis is associated with high risk of mortality and morbidity [4,5]. We report our experience of one case that was encountered at our institution. Institutional review board ethics approval and consent from the patient's power of attorney were obtained.

\section{Case Presentation}

An 83 years old female patient was presented to the emergency department after a simple mechanical fall at her home. There was no history of any previous fall and therefore bilateral fracture can only be contributed to this one mechanical fall event. No prodromal symptoms prior to the fall. She was ambulating with walker at baseline prior to the fall. Her past medical history includes asthma with a recent intubation due to influenza exacerbation, depression, Lewy body dementia with chronic gait disturbance, Parkinson's disease, hypertension, and paroxysmal atrial fibrillation. The anesthesia team felt that the patient is optimized to proceed for surgery and a pre-operative optimization consult for her cardiopulmonary status was not done to avoid surgery delay. The patient was classified by the anesthesia team as ASA 3. Her clinical examination mainly showed left hip tenderness with restricted and painful range of motion with associated left hip shortening and external rotation. The Emergency team consulted the Orthopedics team thinking it is only an isolated unilateral hip fracture case. During the Orthopedic assessment 
and radiographs review, the right hip looked fractured in addition to the left. The radiographs showed bilateral sub-capital femoral neck fractures. Both were fully displaced (Garden type IV) but the left side was more displaced and shortened (Picture 1). The patient was taken the operative room on the next day 16 hours after the admission. She underwent a single stage bilateral cemented bipolar hemiarthroplasty using Exeter Stryker femoral stem with bipolar components (Picture 2). It was done through a direct lateral approach in a lateral decubitus position. The patient was repositioned in the middle of the case for the other hip surgery. The procedure was done under a general anesthetic. The total surgical time was two hours and twenty-two minutes, and the estimated blood loss was about $600 \mathrm{cc}$ and there were no reported peri-operative cardiac or respiratory complications apart from a transient oxygen requirement on post-operative day 2 secondary to mild pulmonary edema which resolved quickly with a short diuretic course. During that period, her troponin reached $152 \mathrm{ng} / \mathrm{L}$ without presence of any ECG changes. The internal medicine service was consulted during that time before they signed off the next day on post-operative day 4 when she was off Oxygen. Her preoperative hemoglobin was $110 \mathrm{~g} / \mathrm{L}$ and it dropped gradually post operatively and reached $73 \mathrm{~g} / \mathrm{L}$ on the second post-operative day which required transfusion of two units of PRBCs. Physiotherapy was involved post operatively for weight bearing as tolerated on both sides. She was transferred after that to a rehabilitation hospital for further recovery. Her last follow up was four months post operatively and she was recovering within expected limits at that point. The patient continued to ambulate with a walker after her surgery until she passed away about 11 months postoperatively due to a decline in her dementia which made the family and the power of attorney procced to palliative care.

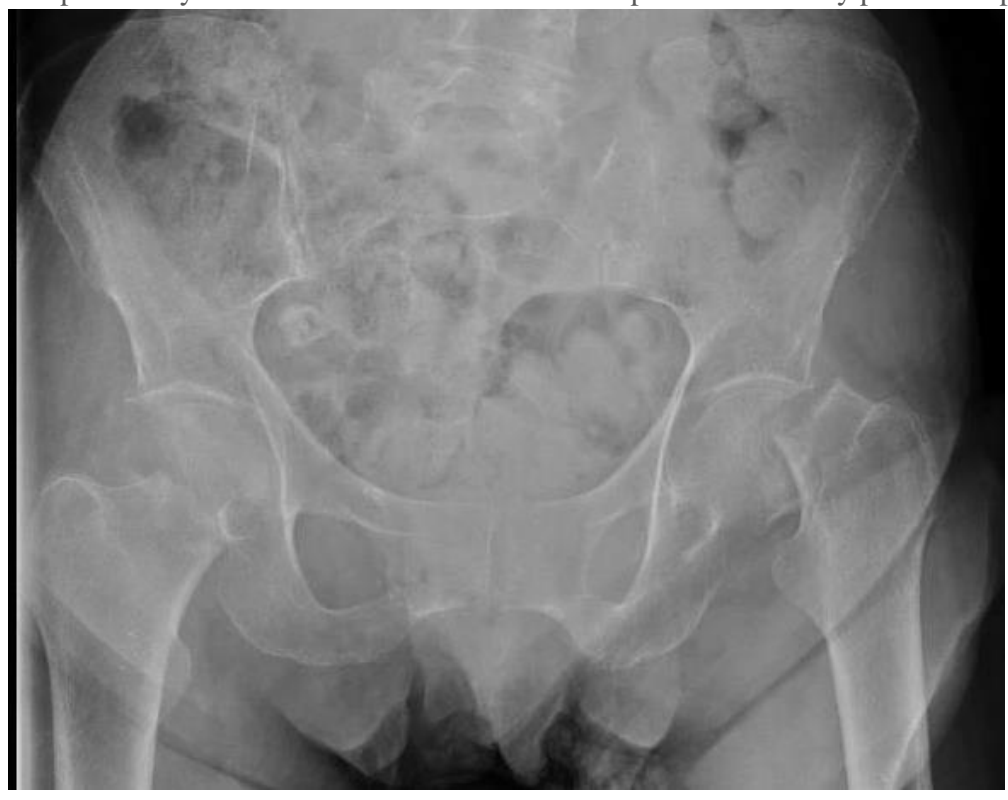

Picture 1: Anterioposterior radiograph of the pelvis showing bilateral femoral neck displaced fractures (Garden type IV).

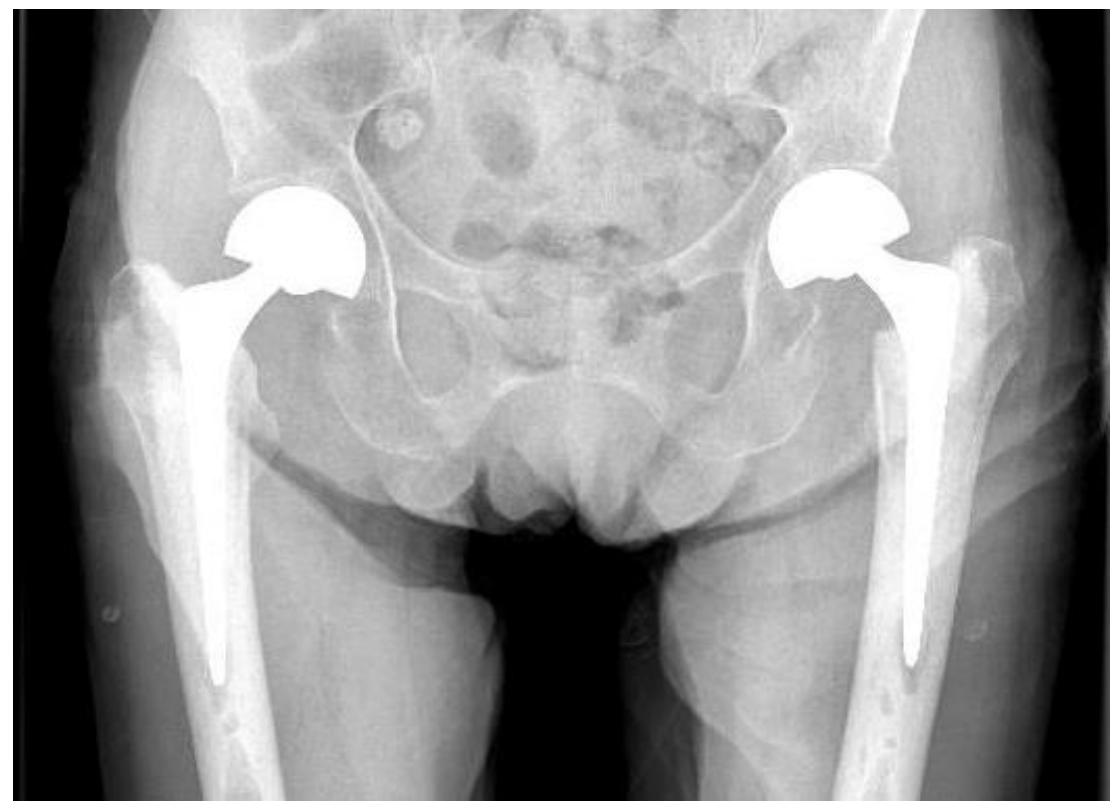

Picture 2: Anterioposterior radiograph of the pelvis showing bilateral bipolar cemented hemiarthroplasty 


\section{Discussion}

Bilateral femur neck fractures in elderly people is not a common diagnosis. In fact, most of the previously reported cases of bilateral femur neck fractures happened in high energy trauma setting or due to electroconvulsive therapy [5]. Such pathology can be a result of non traumatic bone disease like chronic kidney disease, long steroid usage, post local radiation, metabolic bone disease or cancer, and osteoporosis [6-8]. Managing unilateral hip fractures is practiced frequently while bilateral hip fractures could have some diagnostic and therapeutic challenges given its rareness. As a result, Sood et al. recommended in 2009 doing bilateral anterioposterior radiographs for hip fractures which is currently the standard in most centers [7]. In our case, the right sided fracture was initially missed by the Emergency team and that shows the importance of looking for additional fractures during the assessment of hip fracture cases. Some of the similar cases in the literature were treated with uncemented arthroplasty. We think doing cemented hemiarthroplasty should not increase the surgical time significantly even with the inclusion of the repositioning time if needed. Cemented implants reduce the risk periprosthetic fracture and allow for better functional outcomes at follow up [9]. Having bilateral cemented stems did not lead to any significant cardiopulmonary issues as can often be concerned with so called cement syndrome.

To conclude, it is important for care givers of the Orthopedic patients starting from the Emergency department to the Orthopedic floor to be aware of the possibility of experiencing such injury in the elderly people after simple domestic fall even in the absence of chronic medical diseases that could compromise the bone quality. Physicians should consider the possibility of bilateral hip fractures particularly in patients who have baseline dementia or communication difficulties. It is very important to emphasize on the importance of obtaining an AP pelvis X-ray on regular basis for cases with hip fracture to make sure that an associated fracture is ruled out since clinical examination in such patients can be unreliable and leg will not necessarily appear short and externally rotated especially when compared to the other leg in cases of bilateral hip fractures. Early intervention for hip fractures is important and that this is more important in bilateral hip fractures. Multi-disciplinary care and work up are necessary to mitigate complications that are common in all hip fracture patients.

\section{References}

1. Carpintero P, Abad JA, Urbano D, Jimenez-Sanchez C (2006) Simultaneous bilateral fracture of femoral neck in elderly patients: report on two cases. European journal of orthopaedic surgery \& traumatology : orthopedie traumatologie. 16(2):172-4.

2. Popescu D, Trandabat C, Puha B, Veliceasa B, Alexa O (2016) Management of bilateral femoral neck fracture in a nonagenarian patient -- case report. Revista medico-chirurgicala a Societatii de Medici si Naturalisti din Iasi. 120(2):376-9.

3. Van der Zeeuw FT, Weeda VB, Vrouenraets BC (2016) Simultaneous bilateral hip fractures following a simple fall in an elderly patient without predilecting comorbidities. Journal of surgical case reports. 2016(5).

4. Kumar S, Petros JG, Sheehan LJ, Sullivan R (1997) Simultaneous bilateral femoral-neck fractures in an elderly woman. The American journal of emergency medicine. 15(6):619-20.

5. Park JH, Jeong HJ, Shin HK, Kim E, Ko TS, Choi YM (2015). Simultaneous Bilateral Fracture of Femoral Neck in Korea: A Case Report. Hip \& pelvis. 27(1):53-6.

6. Vijayvargiya M, Shetty V, Makwana K, Agarwal N (2017). Bilateral simultaneous neck femur fracture following domestic fall in an elderly patient: a rare case report. Revista brasileira de ortopedia. 52(3):363-5.

7. Sood A, Rao C, Holloway I (2009) Bilateral femoral neck fractures in an adult male following minimal trauma after a simple mechanical fall: a case report. Cases journal. 2(1):92.

8. McGoldrick NP, Dodds MK, Green C, Synnott K (2013) Management of simultaneous bilateral neck of femur fractures in an elderly patient. Geriatric orthopaedic surgery \& rehabilitation. 4(3):71-3.

9. Blankstein M, Lentine B, Nelms N (2020) The Use of Cement in Hip Arthroplasty: A Contemporary Perspective. Journal of the American Academy of Orthopaedic surgeons. 28(14): 586-94

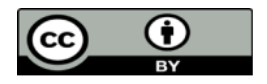

This work is licensed under Creative Commons Attribution 4.0 License

To Submit Your Article Click Here: Submit Manuscript

DOI: $10.31579 / 2690-1897 / 096$

\author{
Ready to submit your research? Choose Auctores and benefit from: \\ $>$ fast, convenient online submission \\ $>$ rigorous peer review by experienced research in your field \\ $>$ rapid publication on acceptance \\ $>$ authors retain copyrights \\ $>$ unique DOI for all articles \\ $>$ immediate, unrestricted online access
}

At Auctores, research is always in progress.

Learn more https://auctoresonline.org/journals/journal-of-surgical-casereports-and-images 